\title{
Primary Medical Effects and Economic Impact of Anastomotic Leakage in Patients with Colorectal Cancer. A Middle-Income Country Perspective
}

\author{
Etele Élthes ${ }^{1,2}$, Árpád Török1,2, Márton Dénes', Radu Mircea Neagoe1, Daniela Sala1, \\ János Székely³ \\ 1 2nd Surgery Department, Mureș County Emergency Clinical Hospital, Târgu Mureș, Romania \\ 2 University of Medicine, Pharmacy, Science and Technology, Târgu Mureș, Romania \\ 3 Department of Orthopedics and Traumatology, Mureș County Emergency Clinical Hospital, Târgu Mureș, Romania
}

\section{CORRESPONDENCE \\ Árpád Török \\ Str. Pârâului nr. 36 \\ Sâncraiu de Mureș, Romania \\ Tel: +40 533125 \\ E-mail: torokaea@yahoo.com}

\section{ARTICLE HISTORY}

Received: June 18, 2020

Accepted: September 2, 2020

\section{ABSTRACT}

Introduction: Anastomotic leakage is one of the most serious surgical complications that can increase the potential postoperative morbidity, mortality, and overall costs of patient care. Aim of study: To assess the economic burden of anastomotic leakage and to estimate its major clinical effects on patient evaluation. Materials and methods: We retrospectively reviewed singlesurgeon data about patients who underwent surgical intervention for colorectal cancer at the 2nd Surgery Department of the Mureș County Emergency Clinical Hospital between January 2019 and July 2020. We assessed general characteristics, surgical data, postoperative information, oncologic results, and financial aspects for each patient. Depending on the presence of anastomotic leakage, patients were divided into two groups: a study group (SG) - patients with postoperative anastomotic failure, and a control Group (CG) - patients without postoperative anastomotic failure. Results: Patients with anastomotic leakage presented increased use of antibiotics, greater number of surgical reinterventions, longer period of intensive care treatment, prolonged hospitalization, increased overall costs, and significantly greater financial loss for the hospital. Conclusion: Anastomotic leakage leads to important negative effects, including longer hospitalization, prolonged intensive care unit stay, greater incidence of surgical reintervention, increased hospitalization costs, and significant financial loss.

Keywords: anastomotic leakage, economic burden, medical effects, hospitalization costs

\section{INTRODUCTION}

Anastomotic leakage is one of the most serious surgical complications that can occur in the postoperative period. Studies report rates from $1.5 \%$ to $16 \%$ for anastomotic leaks (ALs) following colorectal cancer surgery. These complications increase postoperative morbidity, mortality, and the overall costs of pa- 
tient care. Clinical manifestations of ALs will often lead to hospital readmission, causing considerable additional medical and financial burden on both patients and healthcare providers. However, the impact of ALs on hospitalization costs varies across different economies, especially in low- and middle-income countries. Financial burden causes additional challenges due to the possibility of limited resources. Recently conducted studies have highlighted that ALs increase total hospitalization costs by $0.5-1.9$ times. Therefore, a survey of their primary medical effects and financial consequences represents an important guide for health professionals. ${ }^{1-5}$

\section{AIM OF STUDY}

The primary objective of the study was to assess the economic burden of anastomotic leakage and to estimate its major medical effects throughout the patients' clinical evaluation.

\section{MATERIALS AND METHODS}

\section{Study design}

The study included 120 patients who underwent surgery for colorectal cancer at the 2nd Surgery Department of the Mureş County Emergency Clinical Hospital from Târgu Mureş between January 2019 and July 2020. In order to reduce the impact of various surgical habits or experience, only cases handled by the same surgical team were analyzed. An electronic database was created using the H3 Concept Healthcare Electronical System, including information about patient admission, diagnosis, laboratory and imaging investigations, surgical procedures, medication, materials used during hospital stay, and hospitalization costs. The system provides reliable information for several time periods: prior to admission, during admission, short-term follow-up, and readmissions. Exclusion criteria included age $<18$ years, surgery in emergency conditions, and all cases where anastomosis was not possible and stoma formation was required during the surgical intervention.

\section{Variables and study groups}

For each patient, multiple variables were evaluated:

- general characteristics: age, gender, tumor location, anemia at the time of admission;

- surgical assessment: main surgical procedure, protective stoma formation, anastomosis, execution of anastomosis, type of anastomosis, duration of surgery, mean intraoperative blood loss;

- postoperative data: anemia during follow-up, start of bowel motility, start of oral feeding, development of $\mathrm{AL}$, onset of $\mathrm{AL}$, debit of $\mathrm{AL}$, surgical reintervention, intensive care unit (ICU) stay, length of hospital stay, 30-day readmission, length of secondary hospital stay, in-hospital mortality;

- oncologic outcome: local tumoral spread, distant metastasis, TNM staging;

- financial aspects: costs for hospital stay, laboratory tests, radiological investigations, surgical treatment, and medication; DRG index, hospital income, index hospitalization costs, hospital profit or loss.

Based on hemoglobin $(\mathrm{Hb})$ levels, perioperative anemia was categorized into mild $(\mathrm{Hb}>11 \mathrm{~g} / \mathrm{dL})$, moderate $(\mathrm{Hb}$ $8-11 \mathrm{~g} / \mathrm{dL})$, and severe $(\mathrm{Hb}<8 \mathrm{~g} / \mathrm{dL})$. Return of bowel motility was categorized into average (1-4 days) and late return ( $>5$ days). Oral feeding was categorized into early (on postoperative day 1-2) and late oral feeding (after the return of bowel motility). Based on the onset of AL, we distinguished early (1-4 days), moderate (5-10 days), and late ( $>30$ days) occurrence of AL. For the classification of anastomotic failure, we used the grading system proposed by the International Study Group of Rectal Cancer: grade A - asymptomatic leakage; grade B - requires active intervention without relaparotomy; grade $\mathrm{C}$ - requires relaparotomy. Length of stay in the ICU was categorized as follows: without AL, short (1-2 days), and prolonged ( $>3$ days). Hospitalization was categorized into primary or index hospitalization (during which the surgical intervention was performed in order to treat the colorectal cancer) and secondary hospitalization (following readmission for complications).

Depending on the presence of $\mathrm{AL}$, patients were divided into two groups: a study group (SG) - patients with postoperative anastomotic failure; and a control group (CG) - patients who did not develop such a complication after surgical intervention.

\section{Statistical analysis}

Data were collected into an electronic database using Microsoft Excel. Statistical analysis was performed using GraphPad Instat software (GraphPad Software, Inc., San Diego, United States of America). Qualitative data were expressed as integer values and percentages, while quantitative results were expressed as mean and median, after normality testing was performed. The statistical difference 
TABLE 1. Major medical effects of anastomotic leakage

\begin{tabular}{lccc}
\hline & $\begin{array}{c}\text { Patients with AL } \\
\mathbf{n = 1 2}\end{array}$ & $\begin{array}{c}\text { Patients without AL } \\
\mathbf{n}=\mathbf{1 0 8}\end{array}$ & p value \\
\hline Antibiotic use, $\mathrm{n}(\%)$ & & & \\
$\quad$ Prophylactic & $0(0)$ & $95(87.96)$ & 0.0001 \\
$\quad$ Long-term treatment & $12(100)$ & $13(12.04)$ & 0.0001 \\
Necessity of relaparatomy, $\mathrm{n}(\%)$ & $9(75)$ & $7(6.48)$ & 0.0001 \\
Stoma formation during reintervention, $\mathrm{n}(\%)$ & $9(75)$ & $0(0)$ & - \\
Length of ICU stay & & & 0.0001 \\
$\quad$ No ICU stay & $2(16.67)$ & $13(12.04)$ & 0.0037 \\
1-2 days & $6(50)$ & $6(5.56)$ & 0.0090 \\
$\quad$ 3 days & $4(33.33)$ & 10.48 & 0.0001 \\
Average length of index hospitalization, days & 17.41 & $4(3.70)$ & 0.0216 \\
In-hospital mortality, $\mathrm{n}$ (\%) & $3(25)$ & $11(10.18)$ & 0.3914 \\
30-day readmission, $\mathrm{n}$ (\%) & $3(25)$ & 5.72 & 0.1001 \\
Average length of second hospitalization, days & 7.67 & & \\
\hline
\end{tabular}

AL - anastomotic leakage; ICU - intensive care unit; Index hospitalization - primary hospital stay prior to surgical intervention; Secondary hospitalization - hospital stay after readmission

between groups regarding quantitative data was calculated using Student's t test or Mann-Whitney test when appropriate. Categorical data was analyzed using Fisher's exact test. The level of statistical significance was set at a p value of 0.05 , with a confidence interval of $95 \%$ for all calculated parameters.

\section{RESULTS}

A short summary of the major medical effects of anastomotic leakage is presented in Table 1.
Patients in the SG received prolonged antibiotic therapy during hospitalization, while patients in the CG received mostly prophylactic treatment $(\mathrm{p}=0.0001)$. Surgical reintervention was also carried out in a higher proportion in patients from the SG ( $p=0.0001), 75 \%$ of these patients requiring a second laparotomy in order to treat complications caused by the fistula. Most of these cases required anastomotic takedown and stoma formation. Regarding ICU stay, the majority of patients in the CG did not require intensive care treatment $(\mathrm{p}=0.0001)$. On the other hand, patients who developed ALs spent longer periods in the

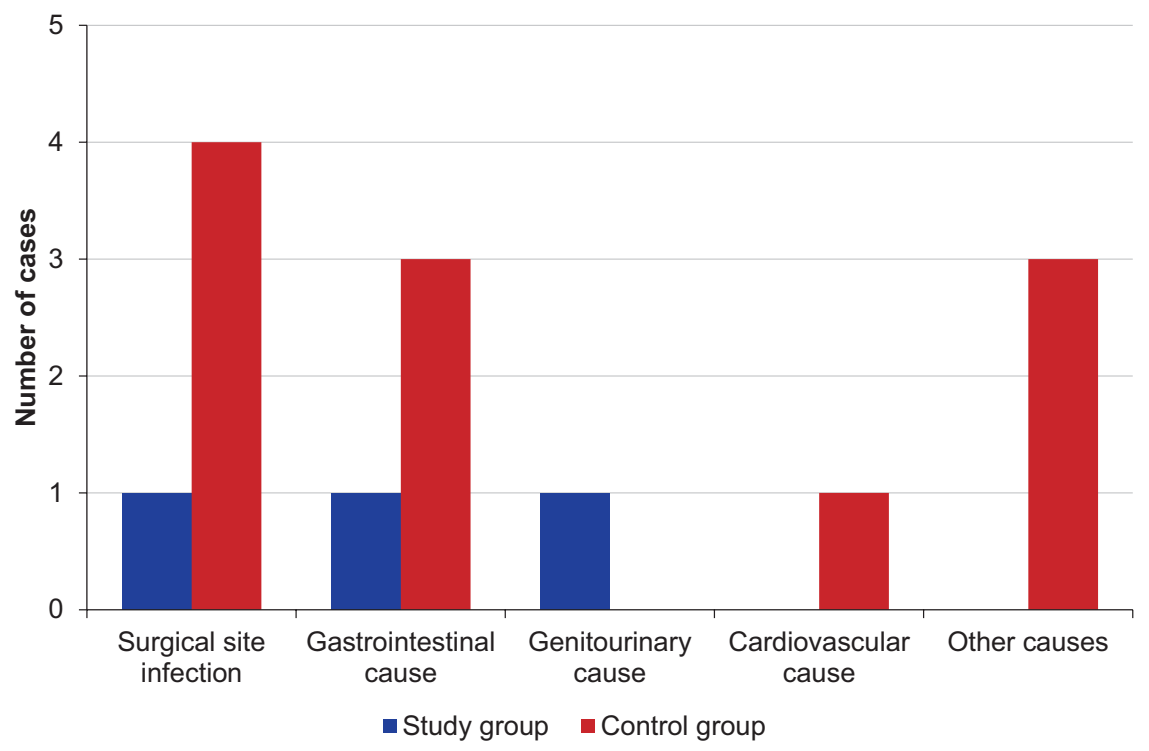

FIGURE 1. Primary reasons for 30-day readmission 
TABLE 2. Financial aspects in patients with and without anastomotic leakage

\begin{tabular}{lccc}
\hline & $\begin{array}{c}\text { Patients with AL } \\
\mathbf{n = 1 2}\end{array}$ & $\begin{array}{c}\text { Patients without AL } \\
\mathbf{n = 1 0 8}\end{array}$ & p value \\
\hline Average costs for laboratory test & 70.09 & 47.92 & 0.5260 \\
Average costs for radiological invest. & 5.94 & 4.06 & 0.0303 \\
Average costs for surgical treatment & 440.3 & 557.92 & 0.1400 \\
Average costs for medication & 308.49 & 208.82 & 0.0285 \\
Average index hospitalization costs & 1973.32 & 1181.97 & 0.0009 \\
Average DRG of treated patients & 3.69 & 3.31 & 0.3731 \\
Average loss-profit/patient & -754.5 & +45.6 & 0.0032 \\
\hline
\end{tabular}

All values are calculated in EUR.

ICU ( $1-2$ days $\mathrm{p}=0.0037 ;>3$ days $\mathrm{p}=0.0090)$. Index hospitalization was also significantly longer $(\mathrm{p}=0.0001)$ for patients from the SG, with an average of 17.41 days. There were no significant differences between the two groups regarding the length of secondary hospitalization. The primary cause for 30-day readmission varied in the two groups and included the following: surgical site infection (SG - 1, $\mathrm{CG}-4$ ), gastrointestinal cause ( $\mathrm{SG}-1, \mathrm{CG}-3$ ), genitourinary cause ( $\mathrm{SG}-1, \mathrm{CG}-0$ ), cardiovascular cause (SG - 0, CG - 1), and other cause (SG - 0, CG - 3) (Figure 1). In-hospital mortality was also significantly higher in patients with $\mathrm{AL}(\mathrm{p}=0.0216)$.

Results regarding the financial aspects are presented in Table 2.

While costs for laboratory tests and surgical treatment did not show important dissimilarities, costs for radiological examinations $(\mathrm{p}=0.0303)$ and medication $(\mathrm{p}=$
0.0285) were significantly higher in case of patients with ALs. The DRG-based case coefficient was nearly similar, without statistically important differences, while the index hospitalization costs were significantly higher for patients with anastomotic leakage $(p=0.0009)$. Furthermore, the presence of AL determined significant financial loss for the hospital budget $(\mathrm{p}=0.0032)$. When analyzing each factor individually (Figure 2), we observed that prolonged ICU stay $(\mathrm{p}=0.0458, \mathrm{OR}=4.98, \mathrm{RR}=1.8)$, surgical reintervention $(\mathrm{p}=0.0111, \mathrm{OR}=5.333, \mathrm{RR}=1.9)$, anastomotic leakage $(\mathrm{p}=0.0001, \mathrm{OR}=34.89, \mathrm{RR}=2.4)$, advanced stages of cancer $(\mathrm{p}=0.033, \mathrm{OR}=2.65, \mathrm{RR}=1.6)$, perioperative anemia $(\mathrm{p}=0.0522, \mathrm{OR}=7.294, \mathrm{RR}=1.9)$, tumors with distal localization $(\mathrm{p}=0.0215, \mathrm{OR}=3.122, \mathrm{RR}=1.6)$, and advanced age $(\mathrm{p}=0.0046, \mathrm{OR}=3.438, \mathrm{RR}=1.8)$ were independent risk factors contributing to the increase of hospitalization costs.

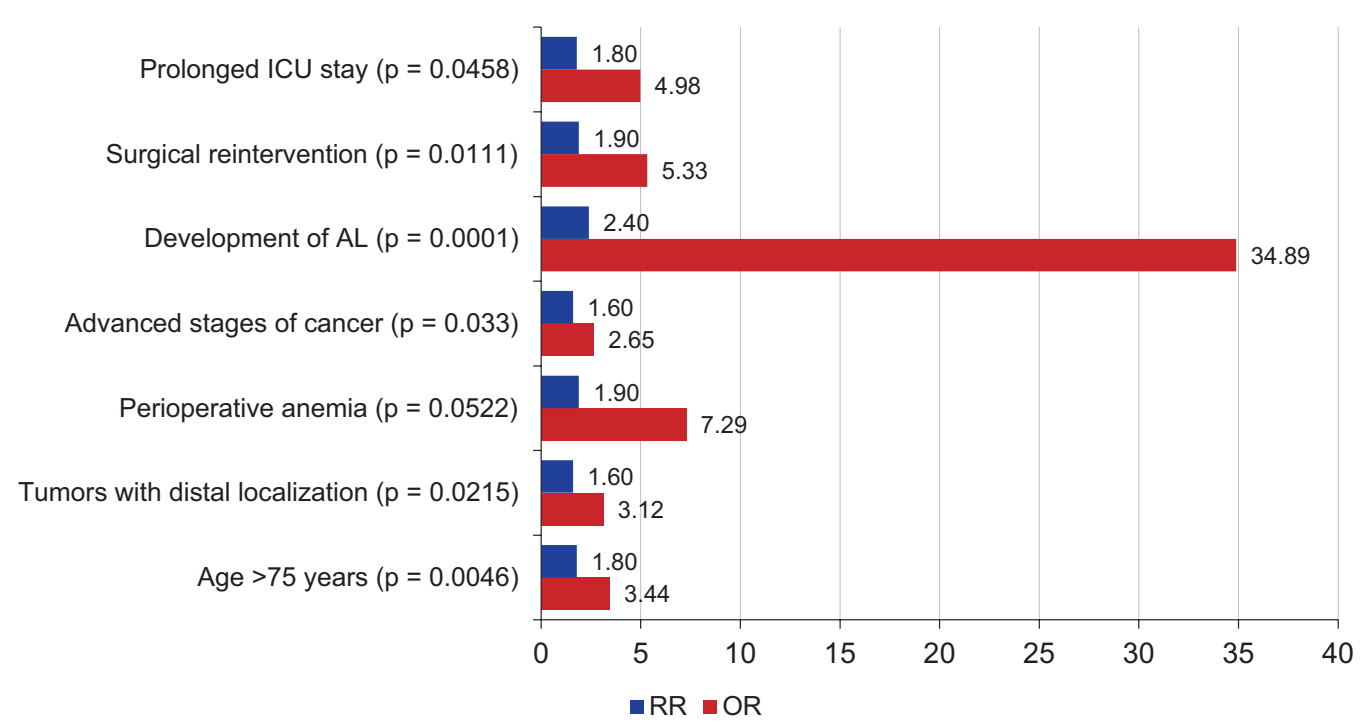

FIGURE 2. Factors independently affecting increase of hospitalization costs 


\section{DISCUSSIONS}

\section{Antibiotic usage}

The present study found that in case of anastomotic leakage, the use of antibiotics increased significantly. Only $12.03 \%$ of patients in the CG received sustained antibiotic treatment; the rest presented favorable evolution with prophylactic antibiotic therapy. All patients with anastomotic leakage required prolonged medication in order to treat the septic complications of AL. Ribeiro Jr et al. reported similar results, highlighting that ALs increased antibiotic use by nearly $70 \% .^{6}$ Similar results were found in other studies as well. ${ }^{7}$

\section{Surgical reintervention and quality of life}

In the postoperative period, a second laparotomy was necessary in nine patients (75\%) in the SG and seven patients (6.48\%) in the CG. It can be stated that ALs had a strong influence on the surgical reintervention rate, causing additional stress in the healing process of patients. All C-grade ALs were operated, anastomotic takedown and stoma formation being applied in the majority of cases. Stoma formation has seriously affected the patients' quality of life, as confirmed by other, similar studies. ${ }^{8,9}$

\section{Intensive care unit stay}

In the present study, $83.33 \%$ of patients in the SG required ICU admission and treatment, compared to only $17.59 \%$ of patients from the CG. In a study based on 1,684 intestinal resections, Byrn et al. observed that the presence of ALs had a strong influence on the length of stay in the ICU. ${ }^{10}$ Dale et al. also highlighted prolonged ICU stays in case of patients with anastomotic leakage. ${ }^{11}$

\section{Hospitalization period and readmissions}

Regarding the length of hospitalization, anastomotic leakage seemed to influence the index hospitalization in a significant manner. The hospitalization of patients with AL was one week longer on average compared to patients with anastomotic integrity. Hammond et al. also found a significantly longer hospitalization period. ${ }^{12}$ The secondary hospitalization was similar among patients with and without AL. In contradiction with our results, several studies found that the secondary hospitalization was also significantly prolonged due to the presence of anastomotic leakage. ${ }^{13}$
We observed different reasons for hospital readmission in the two studied groups. The main reasons for hospital readmission for patients with anastomotic leakage were surgical site infection, urinary infection, and stenosis of the terminal colostomy. Meanwhile, in case of patients without AL in the postoperative period, surgical complications developed in only a few cases (bowel obstruction, surgical site infection). Other reasons for rehospitalization included medical conditions such as pneumonia, acute myocardial infarction, and abdominal pain (without surgical cause). Although twice as many patients with anastomotic leakage were forced to attend a second hospital admission (25\%), the statistical analysis did not show significant differences between the two groups, probably due to the smaller sample size. Krell et al. found that hospital readmissions were more frequently caused by postoperative complications. ${ }^{14}$ It is well known that the development of anastomotic leakage increases morbidity and mortality in a significantly manner. Many studies found that anastomotic leakage has a significant negative impact on the postoperative evolution of patients. ${ }^{15,16}$

\section{Financial considerations}

In terms of economic impact, total costs were considerably greater for patients with ALs compared to patients without this complication. The DRG-based case index did not differ notably; as a result, hospital income after a resolved case was almost identical in the two groups. Therefore, patients with anastomotic leakage produced a major loss for the hospital, with an average of $€ 750$ per patient. Meantime, hospital profit after a patient without complications was only $€ 45$ on average. Consequently, it is easy to understand that ALs have devastating economic consequences. Other studies presented similar results. ${ }^{17,18}$ Multivariate analysis identified multiple factors independently affecting the elevation of hospitalization costs. Springer et al. found that ALs and the necessity of surgical reintervention significantly increased overall costs. ${ }^{19}$ Furthermore, Macafee et al. identified advanced stages of cancer and distal tumor localization as potential factors contributing to excessive hospitalization costs, ${ }^{20}$ while Feng et al. observed that perioperative anemia has significant effects on the financial balance. ${ }^{21}$

\section{CONCLUSION}

In conclusion, anastomotic leakage leads to important medical effects including longer hospitalization, prolonged intensive care unit stay, and greater incidence of surgical 
reintervention. An important economic burden can also be noticed, increasing hospitalization costs by 1.66 times and resulting in significant financial loss for the hospital.

\section{CONFLICT OF INTEREST}

Nothing to declare.

\section{REFERENCES}

1. Thomas MS, Margolin DA. Management of colorectal anastomotic leak. Clin Colon Rectal Surg. 2016;29:138-144.

2. La Regina D, Di Giuseppe M, Lucchelli M, et al. Financial impact of anastomotic leakage in colorectal surgery. J Gastrointest Surg. 2019:23:580-586

3. Fouda E, El Nakeeb A, Magdy A, Hammad EA, Othman G, Farid M. Early detection of anastomotic leakage after elective low anterior resection. $J$ Gastrointest Surg. 2011;15:137-144.

4. Ha GW, Kim JH, Lee MR. Oncologic impact of anastomotic leakage following colorectal cancer surgery: a systematic review and metanalysis. Ann Surg Oncol. 2017;24:3289-3299.

5. Wan Y, Lim S, Riebman J, Jamous N, Gao X. Clinical and economic burden associated with anastomotic leak after colorectal surgeries in the United Kingdom. Gut. 2014;63:A132.

6. Ribeiro U Jr, Tayar DO, Ribeiro RA, Andrade P, Junqueira SM Jr. The clinical and economic burden of colorectal anastomotic leaks: middleincome country perspective. Gastroenterology Research and Practice. 2019:2879049

7. Kobayashi M, Mohri Y, Ohi M, et al. Risk factors for anastomotic leakage and favorable antimicrobial treatment as empirical therapy for intraabdominal infection in patients undergoing colorectal surgery. Surg Today. 2014;44:487-493.

8. Fraccalvieri D, Biondo S, Saez J, et al. Management of colorectal anastomotic leakage: differences between salvage and anastomotic takedown. Am J Surg. 2012;204:671-676
9. Anaraki F, Vafaie M, Behboo R, Maghsoodi N, Esmaeilpour S, Safaee A. Quality of life outcomes in patients living with stoma. Indian J Palliat Care. 2012:18:176-180.

10. Byrn JC, Schlager A, Divino CA, Weber KJ, Baril DT, Aufses AH Jr. The management of 38 anastomotic leaks after 1.684 intestinal resections. Dis Colon Rectum. 2006;49:1346-1353.

11. Dale CD, Mcloone P, Sloan B, et al. Critical care provision after colorectal cancer surgery. BMC Anesthesiol. 2016;16:94.

12. Hammond J, Lim S, Wan Y, Gao X, Patkar A. The burden of gastrointestinal anastomotic leaks: an evaluation of clinical and economic outcomes. $J$ Gastrointest Surg. 2014;18:1176-1185.

13. Nikolian VC, Kamdar NS, Regenbogen SE, et al. Anastomotic leak after colorectal resection: A population-based study of risk factors and hospital variation. Surgery. 2017:161:1619-1627.

14. Krell RW, Girotti ME, Fritze D, Campbell DA, Hendren S. Hospital readmission after colectomy: a population based study. J Am Coll Surg. 2013;217:1070-1079.

15. Boström P, Haapamäki MM, Rutegård J, Matthiessen P, Rutegård M. Population-based cohort study of the impact on postoperative mortality of anastomotic leakage after anterior resection for rectal cancer. BJS Open. 2018;3:106-111

16. Choudhuri $A H$, Uppal R. Predictors of septic shock following anastomotic leak after major gastrointestinal surgery: An audit from a tertiary care institute. Indian J Crit Care Med. 2013;17:298-303.

17. Lee SW, Gregory D, Cool CL. Clinical and economic burden of colorectal and bariatric anastomotic leaks. Surg Endosc. 2020;34:4374-4381.

18. Ashraf $S Q$, Burns EM, Jani A, et al. The economic impact of anastomotic leakage after anterior resections in English NHS hospitals: are we adequately remunerating them? Colorectal Dis. 2013;15:e190-198.

19. Springer JE, Doumouras AG, Saleh F, et al. Drivers of Inpatient Costs After Colorectal Surgery Within a Publicly Funded Healthcare System. Dis Colon Rectum. 2019;62:747-754.

20. Macafee DA, West J, Scholefield JH, Whynes DK. Hospital costs of colorectal cancer care. Clin Med Oncol. 2009;3:27-37.

21. Feng S, Greenberg J, Moloo H, Thavorn K, Mclsaac DI. Hospital cost associated with anemia in elective colorectal surgery: a historical cohort study. Can J Anesth. 2019;66:877-885. 